\title{
Assessment and associated factors of suicidal behaviour among cancer patients visiting the oncology outpatient unit in Mekelle oncologic clinics, Tigray, Ethiopia: a cross-sectional study
}

abreha Tsegay Gebreselassie ( $\nabla$ abrehatsegay@gmail.com )

Mekelle University College of Health Sciences https://orcid.org/0000-0001-7822-1821

workua mekonen metekiya

Mekelle University College of Health Sciences

birhane gebrehiwot beyene

Mekelle University College of Health Sciences

Primary research

Keywords: Suicidal behaviour, Cancer, Factors, Hospital, Ethiopia

Posted Date: April 30th, 2020

DOI: https://doi.org/10.21203/rs.3.rs-23266/v1

License: (c) (i) This work is licensed under a Creative Commons Attribution 4.0 International License.

Read Full License 


\section{Abstract \\ Background}

Cancer is a group of diseases characterized by the uncontrolled growth and spread of abnormal cells. According to estimates from the International Agency for Research on Cancer, there will be 17.0 million new cancer cases in 2018 worldwide. Depression, age, sex, divorced, and hopelessness are of most factors can patient with cancer result in suicidal behaviour. The purpose of this study is to identify and associated factors of suicidal behaviour among cancer patients in Mekelle, Ethiopia.

\section{Methods}

The cross-sectional study design was employed with a total of 345 study subjects in Mekelle, Ethiopia. Suicidal behaviour was measured by the Suicidal Behavior Questionnaire-Revised (SBQ-R) scale. Bivariate and multiple logistic regression analyses were performed to determine between the explanatory and outcome variables.

\section{Results}

The magnitude of suicidal behaviour was $20 \%$. Previously suicidal attempt $[A O R=31.466,95 \% \mathrm{Cl}$ $(14.552,68.042), P<0.0001]$ was associated factor whereas no comorbid physical illness [AOR $=.0 .363$, $95 \%(0.164,0.806)]$ and current treatment regimen (surgery, radiotherapy and palliative care) were significantly protective factors for suicidal behavior.

\section{Conclusion}

No comorbid physical illness, suicide attempt and current treatment regimen were significant factors of suicidal behaviour. Oncologic professionals should assess patient suicidal risk assessment routinely and every professional focuses on management besides the medication.

\section{Background}

Cancer is a group of diseases characterized by the uncontrolled growth and spread of abnormal cells. If the spread is not controlled, it can result in about 1 in every 6 deaths worldwide, more than AIDS, tuberculosis, and malaria combined. Today, it is the second-leading cause of death (following cardiovascular diseases) worldwide and in high- and very high Human Development Index (HDI) countries [1].

According to studies from the International agency for research on cancer (IARC), there will be 17 million new cancer cases in 2018 worldwide, of which six hundred thousand will occur in low HDI countries, 
2.8 million in medium HDI countries, 6.4 million in high-HDI countries, and 7.2 million in very high-HDI countries [2]. By 2040, the global burden is expected to grow to 27.5 million new cancer cases and 16.3 million cancer deaths simply due to the growth and ageing of the population [3].

Diagnosis and treatment should be available, and the early identification of cancer should be prioritized. Detecting cancer at its early stages enables treatment that is generally more effective, less complex and less expensive [4]. Palliative and supportive cares are essential in comprehensive cancer control, and providing access to pain relief is an international legal obligation [5].

Suicide defined, a serious public health problem, as the act of deliberately killing oneself. The expected risk factors for suicide include chronic psychiatric disorder (depression, and neurological disorders) and chronic medical diseases (cancer and HIV infection). Every year, almost one million people die from suicide, $86 \%$ of whom are in low-income countries like our country Ethiopia, and it does not have one single cause and is preventable. World health organization (WHO) estimates for the year 2020, approximately 1.53 million people will die from suicide; and 10 - 20 folds more people will attempt suicide worldwide. These estimates represent on average one death every twenty seconds and one attempt every $1-2$ seconds [6].

We can see one or more of these in someone who have been diagnosed cancer especially early and newly diagnosed contemplating suicide. These are the signs that are generally clear and easy to observe: talking about dying or wanting to die, talking about feeling empty, hopeless, or having no way out of problems, mentioning strong feelings of guilt and shame, talking about not having a reason to live or that others would be better off without them, social withdrawal and isolation, giving away personal items and wrapping up loose ends, saying goodbye to friends and family this is all because of the illness condition, and its severity treatment.

Suicidal behaviour refers to talking about or taking actions related to ending one's own life or thoughts or tendencies that put a person at risk for committing suicide. Suicidal behaviour can, therefore, be conceptualized on a phenotypic continuum ranging from suicidal behaviour to suicidal attempt and completed suicide.

A surveillance analyses study done in the United States, Los Angeles, showed that of 467,368 women with gynecologic cancers, there were 309 (0.07\%) suicides during the study period; specifically, uterine cancer $88.2 \%$, cervical cancer $78.1 \%$, and ovarian cancer $73.6 \%$; all, $P<0.05$ ) [7].

According to the study done in Canada revealed that $15.7 \%$ of patients with Head and Neck Cancer were suicidal 1 year from diagnosis [8]. Whereas another study done in China indicated that suicidal behaviour was $15.3 \%$ in Chinese cancer inpatients [9].

The study conducted in Korea showed that the suicidal behaviour was present in $10.9 \%$ of participants at 1 week and $11.4 \%$ at 1 year after breast cancer surgery [10]. According to the report in USA, New York, 
negative religious coping $(A O R=2.65,95 \% \mathrm{Cl} 1.22-5.74, \mathrm{P}=0.01)$ was associated with an increased risk for suicidal behaviour [11].

A surveillance analyses study done in United States, Los Angeles, showed that white race $(A O R=3.619 \mathrm{Cl}$ : 1.696-7.722), $\mathrm{P}=0.001)$; divorced $(\mathrm{AOR}=1.49, \mathrm{Cl} 1.053-2.112, \mathrm{P}=0.024)$; Cancer stage IV $(\mathrm{AOR}=1.735$, $\mathrm{Cl} 1.147-2.624, \mathrm{P}=0.009)$; cancer type like ovarian cancer $(\mathrm{AOR}=1.991,95 \% \mathrm{Cl} 1.461-2.712, \mathrm{P}<0.001)$ and cervical cancer $(\mathrm{AOR}=1.765,95 \% \mathrm{Cl}=1.290-2.413, \mathrm{P}<0.001)$ were significant factors for suicide [7].

A study done in Colorado, Western United States showed the magnitude of suicidal behaviour ranged greatly from $0.7-46.3 \%$. Commonly identified risk factors for suicidal behaviour were included age, sex, and disease/treatment-related characteristics, as well as psychological constructs including depression, anxiety, hopelessness, existential distress, and social support [12].

Study conducted in China indicated that depression (AOR $=6.41, \mathrm{Cl} 3.30-12.42, \mathrm{P}<0.001)$, anxiety (AOR = $6.93,95 \% \mathrm{Cl} 1.57-30.66, \mathrm{P}=0.011$, moderate to severe pain $(A O R=2.35,95 \% \mathrm{Cl} 1.32-4.17, \mathrm{P}=0.004)$, metastatic cancer $(A O R=2.94, \mathrm{Cl} 1.26-6.98, \mathrm{P}=0.015)$, poor performance status $(A O R=2.01,95 \% \mathrm{Cl}$ $1.11-3.64, \mathrm{P}=0.021)$, surgery $(\mathrm{AOR}=6.62,95 \% \mathrm{Cl} 2.30-19.07, \mathrm{P}<0.001)$, and palliative care $(\mathrm{AOR}=$ $1.90,95 \% \mathrm{Cl} 1.01-3.61, \mathrm{P}=0.049)$ were significantly associated with suicidal behavior [9].

A study done in Taiwan indicated that the first month of cancer diagnosis was associated behaviour of suicide with in the first month ( $A O R=3.47,95 \% \mathrm{Cl} 52.60-4.62)$ and the sixth month following a cancer diagnosis $(\mathrm{AOR}=1.53,95 \% \mathrm{Cl} 51.11-2.12)$ [13].

According to a study conducted in Iceland suicidal behaviour was after a cancer diagnosis (AOR $=1.6$, $95 \% \mathrm{Cl} 1.4-1.9)$. The risk increase was greatest immediately after diagnosis; during the first year after diagnosis $(A O R=2.5,95 \% \mathrm{Cl} 1.7-3.5)$ and thereafter diagnosis $(A O R=1.595 \% \mathrm{Cl} 1.2-1.8)$ [14].

A study done in Korea showed that suicidal behaviour was associated with cancer stage, I stage (AOR = $1.97,95 \% \mathrm{Cl} 1.05-3.69, \mathrm{P}<0.05$,), living alone $(\mathrm{AOR}=3.57,95 \% \mathrm{Cl} 1.05-7.77, \mathrm{P}<0.05)$ after 1 -year diagnosis [15].

A study was done in South Korea showed that the risk of suicide attempts was significantly higher in participants diagnosed with cancer before 45 years of age compared with those diagnosed at 4564 years $(\mathrm{AOR}=3.81,95 \% \mathrm{Cl} 1.07-13.60, \mathrm{P}=0.039)$, and the higher risk of suicide attempts with borderline significance was found in those for whom more than 10 years had passed since diagnosis compared with those for whom the diagnosis was made only $2-10$ years ago $(A O R=3.38,95 \% \mathrm{Cl} 1.98-$ $11.70, P=0.055)[10]$.

Cancer patients are at high risk for suicide, particularly when they are informed about the cancer diagnosis or hospitalized for cancer treatment. Therefore, oncology tertiary healthcare settings like Ayder comprehensive specialized hospital may represent an ideal setting to identify and treat suicidality in cancer patients in Mekelle, Ethiopia. 


\section{Methodology}

Study areas and period

This study was conducted in 2019 at Mekelle, oncology clinics, Ayder Comprehensive Specialized Hospital. According to the Ethiopian central statistical agency report; the total population in 2012 Ethiopian Calendar has been 420,350, which is located in Tigray regional state $783 \mathrm{~km}$ away from Addis Ababa, the capital city of Ethiopia. Oncologic services are given by oncologists and general practitioners. More than 36 health professionals work in an oncologic clinic, out of them, 4 were oncologists. The current flow of oncologic patients on average was 1500 patients per month in Ayder Comprehensive Specialized Hospital, which has 25 beds for inpatient services. The study period was from April 10 to June 10, 2019.

Study design

An institutional-based cross-sectional study was conducted.

Source population and study population

\section{Source population}

All oncologic outpatient unit visitors were in Mekelle, oncologic clinics, Tigray, Ethiopia.

\section{Study population}

All oncologic sampled outpatient unit visitors were in Mekelle, oncologic clinics, Tigray, Ethiopia.

\section{Eligibility criteria}

\section{Inclusion criteria}

- Oncologic outpatient unit visitors, patients who had diagnosed known cancer and aged 18 years and above, patients attending treatment at the oncology clinic during the data collection period were included in the study.

\section{Exclusion criteria}

- Patients who were unable to communicate, severe pain, unable to sign a verbal informed consent and those who had decision incapacity were not be included in the study.

\section{Sample size and sampling procedure}

\section{Sample size}

The sample size was calculated using a single proportion formula and since there is no study published in Ethiopia show the prevalence so that we used $50 \%$. Other assumptions made during the sample size 
calculation are $5 \%$ marginal error (d) and a confidence interval of $95 \%(z a / 2=1.96)$. Based on these assumptions, the sample size calculated as follows:

$n=Z^{2} p q / d 2$

$\mathrm{n}=(1.96)^{2}(0.50 .5) /(0.05)^{2}=384$. But during that study, 39 respondents missed from the study though we tried a $10 \%$ non-response rate, no participants participated. So the final sample size was $\mathbf{3 4 5}$.

Sampling technique and procedure

The systematic sampling technique was employed. The study participants were proportionally taken. Since the ratio of 1500 samples to 345 was 4 , we took every 4 samples were selected.

\section{Data collection procedure}

Face to face interview method using a structured questionnaire was used in this study to identify the magnitude and associated factors of suicidal behaviour such as (1) sociodemographic information, (2) biopsychosocial and (3) suicidal behaviour.

The SBQ-R is a self-report measure of suicidal behaviour. This shortened version of the SBQ consists of four questions to assess suicidal behaviour history, current suicide status and self-appraisal and expectancies about the future likelihood of engaging in suicidality. The magnitude of overall suicidal behaviour (as defined by SBQ-R a total score $\geq 8$ for adult clinical population) and the total score ranges from 3 to 18 .

The Oslo 3-items social support scale (OSSS-3) was used to measure the strength of social support. The scores range from 3-14. A score ranging between 3 and 8 is classified as poor support, a score between 9 and 11 as moderate support, and a score between 12 and 14 as strong support. These three items were considered to be the best predictors of mental health, covering different fields of social support.

Data were collected by seven B.Sc oncology professionals having previous experience of data collection. The principal investigator checked the filled questionnaires for consistency and completeness each day. The questionnaire was translated from English to Tigrigna language by English teacher and retranslated to English by another expert in English. This primary version was made to compare with the original English version to resolve inconsistencies and then the data collectors, who are Tigrigna native speakers, collected data in the Tigrigna questionnaire.

Study variables

Dependent variables

Suicidal behaviour. 
Socio-demographic, medical and psychiatry illnesses and substance.

\section{Operational definitions}

Suicidal behaviour: after the diagnosis of cancer, the patient experience of having recurrent thought of death, ideation, intention, and plan to kill oneself and having organized plan; and based on SBQ-R scale scores $\geq 8$ from 18 , the total scale scores range from 3 to 18 [16].

- 0-7 no suicidal behaviour

- 8-18 suicidal behaviour

Social support: the OSSS-3 sum score can be operationalized into three broad categories of social support [17].

- 3-8 poor social support

- 9-11 moderate social support

- 12-14 strong social support

\section{Data quality assurance}

The pre-test was conducted on a sample of 10\% (34 samples) of the total study population in Quiha General Hospital before one month of data collection and a common understanding was reached between the data collectors. The pre-test questionnaires were not included in the analysis as part of the main study. Data collection was collected within 50 working days. Regular supervision by the principal investigator was done. During data collection, filled questionnaires' were checked for completeness and consistency daily.

\section{Data analysis procedure}

After data collection, filled questionnaires were coded. The data were entered using Epi data version 4.2 statistical software to minimize error that occurs during data entry and exported to SPSS; and analyzed using SPSS version 25. Data cleaning was performed to check for frequencies, accuracy, and consistencies and missed values and variables. The finding of this study was presented using text and tables form the result of frequencies and crosstabs.

A bivariate logistic regression model analysis was done to see the association between the risk factors and outcome variables. Multivariable logistic regression analysis was employed by selecting only variables with a P-value $<0.25$ in the bivariate analysis. The odds ratio with $95 \% \mathrm{Cl}$ was used to measure the strength between dependent and independent variables at P-value $<0.05$ to determine the level of statistical significance. Variables with the $P$ value less than 0.05 in multivariate regression were considered to be potential predictors for suicidal behaviour.

\section{Results}


A total of 345 respondents were enrolled in the study, making a $100 \%$ response rate. Of those enrolled, 164 (47.5) were females. Age who are in 25 - 34 years old were 27 (39.1) had suicidal behaviour whereas 92 (33.3) had no. Participants who had suicidal 38 (55.1) and not suicidal 122(44.2) were single in marital status.

Nearly half of participants 160 (47.5) were married. Concerning educational status, 75 (21.7) of respondents were illiterate and 67 (19.4) of them attended primary school. Regarding occupation, unemployed were 116 (33.6) and 29 (8.4), of them, were daily labourer (Table 1). 
Table 1

Sociodemographic characteristics among cancer patients visiting the oncology outpatient unit in Mekelle oncologic clinics, Tigray, Ethiopia, $2019(\mathrm{~N}=345)$.

\begin{tabular}{|c|c|c|c|}
\hline \multirow[t]{2}{*}{ Variable Category } & & \multicolumn{2}{|c|}{ Suicidal behaviour } \\
\hline & & No & Yes \\
\hline \multirow[t]{4}{*}{ Age } & $18-24$ & $44(15.9)$ & $14(20.3)$ \\
\hline & $25-34$ & $92(33.3)$ & 27(39.1) \\
\hline & $35-45$ & $85(30.8)$ & $18(26.1)$ \\
\hline & $\geq 46$ & $55(20)$ & $10(14.4)$ \\
\hline \multirow[t]{2}{*}{ Gender } & Male & $139(50.4)$ & $42(60.9)$ \\
\hline & Female & $137(49.6)$ & $27(39.1)$ \\
\hline \multirow[t]{3}{*}{ Marital status } & Single & $122(44.2)$ & $38(55.1)$ \\
\hline & Married & 107(38.8) & $24(34.8)$ \\
\hline & Divorced/widowed/separated & $47(17)$ & $7(10.1)$ \\
\hline \multirow[t]{3}{*}{ Ethnicity } & Tigray & $256(92.8)$ & $59(85.5)$ \\
\hline & Afar & $12(4.3)$ & $5(7.2)$ \\
\hline & Amhara & $8(2.9)$ & $5(7.2)$ \\
\hline \multirow[t]{5}{*}{ Educational status } & Illiterate & $64(23.2)$ & 11(15.9) \\
\hline & Read and write only & $29(10.5)$ & $3(4.3)$ \\
\hline & Primary school & $54(19.6)$ & $13(18.8)$ \\
\hline & Second school & $82(29.7)$ & $20(29.0)$ \\
\hline & Tertiary(university) & $47(17.0)$ & 22(31.9) \\
\hline \multirow[t]{4}{*}{ Occupation } & Unemployed & $97(35.1)$ & $19(27.5)$ \\
\hline & Government & $38(13.8)$ & 12(17.4) \\
\hline & Farmer & $88(31.9)$ & $21(30.4)$ \\
\hline & Student & $53(19.2)$ & $17(24.6)$ \\
\hline \multirow[t]{5}{*}{ Income (ETB) } & $500-1000$ & $22(25)$ & $7(23.3)$ \\
\hline & $1001-2501$ & $32(36.4)$ & $10(33.3)$ \\
\hline & $2501-3000$ & $7(8.0)$ & $2(6.70)$ \\
\hline & $3501-5000$ & 13(14.8) & $1(3.3)$ \\
\hline & $\geq 5001$ & 14(15.9) & $10(33.3)$ \\
\hline
\end{tabular}




\begin{tabular}{|llll|}
\hline Variable Category & & \multicolumn{2}{l|}{ Suicidal behaviour } \\
\cline { 3 - 4 } & & No & Yes \\
\hline Living with whom & Alone & $36(13.0)$ & $12(17.4)$ \\
& With family & $128(46.4)$ & $33(47.8)$ \\
& With relative & $112(40.6)$ & $24(34.8)$ \\
\hline Education-related stress & No & $156(73.6)$ & $38(65.5)$ \\
& Yes & $56(26.4)$ & $20(34.5)$ \\
\hline Work-related stress & No & $43(48.9)$ & $11(36.7)$ \\
& Yes & $45(51.1)$ & $19(63.3)$ \\
\hline
\end{tabular}


Table 2

comorbid medical and psychiatric illness characteristics among cancer patients visiting the oncology outpatient unit in Mekelle oncologic clinics, Tigray, Ethiopia, $2019(\mathrm{~N}=345)$.

\begin{tabular}{|c|c|c|c|}
\hline \multirow[t]{2}{*}{ Variables } & \multirow[t]{2}{*}{ Category } & \multicolumn{2}{|c|}{ Suicidal behaviour (20\%) } \\
\hline & & No & Yes \\
\hline \multirow[t]{2}{*}{ Comorbid physical illness } & No & 81.5 & 62.3 \\
\hline & Yes & 18.5 & 37.7 \\
\hline \multirow[t]{7}{*}{ Type/s of physical diagnosis } & Hypertension & 17.6 & 23.1 \\
\hline & TB & 5.9 & 23.1 \\
\hline & HIV/AID & 11.8 & 11.5 \\
\hline & DM & 21.6 & 7.7 \\
\hline & Epilepsy & 15.7 & 7.7 \\
\hline & Asthma & 7.8 & 3.8 \\
\hline & Other $\mathrm{A}$ & 19.6 & 23.1 \\
\hline \multirow[t]{2}{*}{ Previous psychiatry history } & No & 83.3 & 69.6 \\
\hline & Yes & 16.7 & 30.4 \\
\hline \multirow[t]{4}{*}{ History of psychiatric disorder } & Schizophrenia & 63.0 & 42.9 \\
\hline & Major depressive disorder & 15.2 & 28.6 \\
\hline & Bipolar I disorder & 10.9 & 14.3 \\
\hline & Other ${ }^{B}$ & 10.9 & 14.3 \\
\hline \multirow[t]{2}{*}{ Attempt suicide previously } & No & 88.8 & 23.2 \\
\hline & Yes & 11.2 & 76.8 \\
\hline \multirow[t]{2}{*}{ Family history of suicide attempt } & No & 96.4 & 84.1 \\
\hline & Yes & 3.6 & 15.9 \\
\hline \multicolumn{4}{|c|}{$\begin{array}{l}\text { A physical illness that comorbid with cancer includes TB (tuberculosis), HIV/AIDS (Human immune } \\
\text { deficiency virus/Acquired immune deficiency syndrome), and diabetes mellitus (DM). }\end{array}$} \\
\hline \multicolumn{4}{|c|}{$\begin{array}{l}\text { Psychiatric illness that comorbid with cancer includes PTSD (post-traumatic stress disorder), OCD } \\
\text { (obsessive-compulsive disorder) and BDD (body dysmorphic disorder). }\end{array}$} \\
\hline \multicolumn{4}{|c|}{ Other ${ }^{A}$ includes weakness, sepsis, traumatic brain injury (TBI) } \\
\hline \multicolumn{4}{|c|}{ Other ${ }^{B}$ includes PTSD, OCD and BDD. } \\
\hline \multicolumn{4}{|c|}{ Other ${ }^{c}$ includes brain cancer, uterine cancer } \\
\hline
\end{tabular}




\begin{tabular}{|c|c|c|c|}
\hline \multirow[t]{2}{*}{ Variables } & \multirow[t]{2}{*}{ Category } & \multicolumn{2}{|c|}{ Suicidal behaviour (20\%) } \\
\hline & & No & Yes \\
\hline \multirow[t]{7}{*}{ Patient's types of cancer } & Stomach cancer & 26.8 & 46.4 \\
\hline & Liver cancer & 12.7 & 11.6 \\
\hline & Lung cancer & 43.8 & 29.0 \\
\hline & Breast cancer & 4.0 & 4.3 \\
\hline & Cervical cancer & 3.3 & 2.9 \\
\hline & Colon cancer & 4.3 & 1.4 \\
\hline & Other ${ }^{c}$ & 5.1 & 4.3 \\
\hline \multirow[t]{4}{*}{ Cancer stage } & Moderate to severe & 10.1 & 21.7 \\
\hline & Local & 47.5 & 42.0 \\
\hline & Regional & 30.4 & 26.1 \\
\hline & Metastatic & 12.0 & 10.1 \\
\hline \multirow[t]{3}{*}{ Duration of illness before starting treatment } & Less than 1 year & 17.8 & 15.9 \\
\hline & $2-5$ years & 40.2 & 49.3 \\
\hline & $\geq 15$ years & 42.0 & 34.8 \\
\hline \multirow[t]{2}{*}{ Hospital admission } & No & 79.3 & 62.3 \\
\hline & Yes & 20.7 & 37.7 \\
\hline \multirow[t]{4}{*}{ How long admitted } & 1 week & 29.8 & 26.9 \\
\hline & 2 weeks & 21.1 & 34.6 \\
\hline & 3 weeks & 33.3 & 19.2 \\
\hline & one month and above & 15.8 & 19.2 \\
\hline
\end{tabular}

A physical illness that comorbid with cancer includes TB (tuberculosis), HIV/AIDS (Human immune deficiency virus/Acquired immune deficiency syndrome), and diabetes mellitus (DM).

Psychiatric illness that comorbid with cancer includes PTSD (post-traumatic stress disorder), OCD (obsessive-compulsive disorder) and BDD (body dysmorphic disorder).

Other ${ }^{\mathbf{A}}$ includes weakness, sepsis, traumatic brain injury (TBI)

Other ${ }^{\mathrm{B}}$ includes PTSD, OCD and BDD.

Other ${ }^{\mathrm{C}}$ includes brain cancer, uterine cancer 


\begin{tabular}{|c|c|c|c|}
\hline \multirow[t]{2}{*}{ Variables } & \multirow[t]{2}{*}{ Category } & \multicolumn{2}{|c|}{ Suicidal behaviour (20\%) } \\
\hline & & No & Yes \\
\hline \multirow[t]{4}{*}{ Current treatment regimen } & Chemotherapy & 9.8 & 29.0 \\
\hline & Radiotherapy & 53.6 & 50.7 \\
\hline & Palliative therapy & 29.0 & 17.4 \\
\hline & Surgery & 7.6 & 2.9 \\
\hline \multirow[t]{2}{*}{ Current status of treatment } & No & 93.5 & 96.8 \\
\hline & Yes & 6.5 & 3.2 \\
\hline \multicolumn{4}{|c|}{$\begin{array}{l}\text { A physical illness that comorbid with cancer includes TB (tuberculosis), HIV/AIDS (Human immune } \\
\text { deficiency virus/Acquired immune deficiency syndrome), and diabetes mellitus (DM). }\end{array}$} \\
\hline \multicolumn{4}{|c|}{$\begin{array}{l}\text { Psychiatric illness that comorbid with cancer includes PTSD (post-traumatic stress disorder), OCD } \\
\text { (obsessive-compulsive disorder) and BDD (body dysmorphic disorder). }\end{array}$} \\
\hline \multicolumn{4}{|c|}{ Other ${ }^{A}$ includes weakness, sepsis, traumatic brain injury (TBI) } \\
\hline \multicolumn{4}{|c|}{ Other ${ }^{B}$ includes PTSD, OCD and BDD. } \\
\hline Other ${ }^{c}$ includes brain canc & & & \\
\hline
\end{tabular}

\section{Substance}

Regarding the frequency of taking the substance, $(10.5 \% \%)$ participants that had no suicidal behaviour and (15.9\%) participants that had suicidal behaviour smoked a cigarette (Fig. 1).

Comorbid medical and psychiatric illness

From all respondents participated in study $345(20 \%)$ of them had suicidal behaviour. Out of those participants with comorbid physical illness had $37.7 \%$ suicidal behaviour. The magnitude of suicidal behaviour among cancer patient with attempt suicide previously was $76.8 \%$.

The magnitude of suicidal behaviour was higher in respondents with stomach cancer at $46.4 \%$.

Regarding the history of psychiatric disorder, schizophrenia $42.9 \%$, major depressive disorder $28.6 \%$ ) and bipolar I disorder $14.3 \%$ had suicidal behaviour.

The distributions of suicidal behaviour among patients who had a family history of suicide attempt $15.9 \%$ and the stage of cancer participants with local stage were $42.0 \%$ (Table 3 ). 
Table 3

suicidal behaviour assessment among cancer patients visiting the oncology outpatient unit in Mekelle oncologic clinics, Tigray, Ethiopia, 2019 ( $N=345)$.

\begin{tabular}{|llll|}
\hline Variable Category & & \multicolumn{2}{l}{ Suicidal behaviour (20\%) } \\
\cline { 3 - 4 } Lifetime suicidal ideation, intention and attempt & Never & $223(80.8)$ & $0(0.0)$ \\
Frequency suicidal ideation in the past year & Suicidal thought & $36(13.0)$ & $4(5.5)$ \\
Suicidal threats & Intent & $8(2.9)$ & $18(26.1)$ \\
Likelihood of suicide in the future & Suicide attempts & $9(3.3)$ & $47(68.1)$ \\
\cline { 2 - 4 } & Never & $239(86.6)$ & $9(13.0)$ \\
& Once & $34(12.3)$ & $32(46.4)$ \\
& Twice & $2(0.7)$ & $18(26.1)$ \\
& $3-4$ times & $1(0.4)$ & $6(8.7)$ \\
& $\geq 5$ times $)$ & $0(0.0)$ & $4(5.8)$ \\
\cline { 2 - 4 } & No & $268(97.1)$ & $23(33.3)$ \\
& Once & $8(2.9)$ & $39(56.5)$ \\
& Twice and more & $0(0.0)$ & $7(10.1)$ \\
\hline Never & $174(63.0)$ & $0(0)$ \\
& no chance at all & $90(32.6)$ & $7(10.1)$ \\
rather unlikely & $7(2.5)$ & $2(2.9)$ \\
unlikely & $5(1.8)$ & $13(18.5)$ \\
& likely & $0(0.0)$ & $47(68.2)$ \\
\cline { 2 - 4 }
\end{tabular}

Social support

Respondents with poor social support (55.1\%) and Moderate social support (39.1\%) had a higher prevalence of suicidal behaviour than with strong social support $5.8 \%$ (Fig. 1).

Suicidal behaviour Assessment (SBQ-R)

This study found that (80.8\%) never lifetime suicidal ideation, intention and attempt and (68.1\%) suicidal participants had suicide attempt history. The Frequency suicidal ideation in the past year more than half of the participants reported never and one-fourth participants once a time in the past year (Table 3).

Bivariate regression of analysis of suicidal behaviour 
In the bi-variable logistic regression analysis, variables such as diagnosis, educational status, psychiatric comorbidity and alcohol use, hospital admission, current treatment, family history of suicide and previous suicidal attempt were a candidate for multiple logistic regression with $(P$ - value $<0.25)($ Table 4$)$.

Table 4

bivariate regression of analysis of suicidal behaviour among cancer patients visiting the oncology outpatient unit in Mekelle oncologic clinics, Tigray, Ethiopia, $2019(\mathrm{~N}=345)$.

\begin{tabular}{|c|c|c|c|}
\hline Variables & Category & $\operatorname{coR}(95 \% \mathrm{Cl})$ & P-value \\
\hline \multirow[t]{5}{*}{ Educational states } & Illiterate & $.367(.162, .830)$ & .016 \\
\hline & Read and write & $.221(.061, .804)$ & .022 \\
\hline & Primary school & $.514(.234,1.132)$ & .099 \\
\hline & Secondary school & $.521(.258,1.053)$ & .069 \\
\hline & The tertiary school & Reference & \\
\hline \multirow[t]{2}{*}{ Diagnosis of comorbid physical illness } & No & Reference & \\
\hline & Yes & $2.668(1.503,4.736)$ & 0.000 \\
\hline \multirow[t]{2}{*}{ Psychiatric comorbidity } & No & & \\
\hline & Yes & $2.187(1.197,3.996)$ & 0.011 \\
\hline \multirow[t]{2}{*}{ Family history of suicidal attempt } & No & Reference & \\
\hline & Yes & $5.045(2.046,12.436)$ & 0.001 \\
\hline \multirow[t]{4}{*}{ Current treatment regimen } & Chemotherapy & Reference & \\
\hline & Radiotherapy & $.319(.161, .634)$ & 0.01 \\
\hline & Palliative therapy & $.203(.088, .468)$ & 0.000 \\
\hline & Surgery & $.129(.027, .613)$ & 0.010 \\
\hline \multirow[t]{2}{*}{ Hospital admissions } & No & Reference & \\
\hline & Yes & $2.323(1.317,4.098)$ & .004 \\
\hline \multirow[t]{2}{*}{ The habit of drinking alcohol } & No & Reference & \\
\hline & Yes & $2.149(1.106,4.176)$ & 0.024 \\
\hline
\end{tabular}

Multivariable logistic regression factors independently associated with suicidal behaviour

All variables that had $\mathrm{P}<0.25$ in the bivariate analysis were included in multivariate analysis for backward logistic regression. From total variables included in the logistic regression models, two variables were found to be statistically significant at the level of $\mathrm{P}<0.05$ and one variable as protective 
factors. As of this result, participants had no comorbid physical illness $63.7 \%$ [AOR $=.0 .363,95 \%(0.164$, 0.806)] less likely to develop suicidal behaviour than had a comorbid physical illness. Current treatment regimen was also as significant protective factor for suicidal behavior that is radiotherapy $[A O R=.178$, $95 \% \mathrm{Cl}(.066, .479), \mathrm{P}=0.001]$, palliative therapy $[\mathrm{AOR}=.204(.067, .621), \mathrm{P}=0.005]$, and surgery [AOR $=.054,95 \% \mathrm{Cl}(.007, .424), \mathrm{P}=0.006]$.

Regarding previously family suicidal attempt 31 times more likely to develop than respondents didn't attempt suicide previously [AOR $=31.466,95 \% \mathrm{Cl}(14.552,68.042), \mathrm{P}<0.0001]$ (Table 5).

Table 5

Multivariable logistic regression of analysis of suicidal behaviour among cancer patients visiting oncology outpatient unit in Mekelle oncologic clinics, Tigray, Ethiopia, $2019(\mathrm{~N}=345)$.

\begin{tabular}{|llll|}
\hline Variable & Category & AOR(95\%Cl) & P-value \\
\hline Comorbid physical illness & No & $.363(.164, .806)$ & $.013^{*}$ \\
\cline { 2 - 4 } & Yes & Reference & \\
\hline Current treatment regimen & Chemotherapy & Reference & $.00^{*}$ \\
\cline { 2 - 4 } & Radiotherapy & $.178(.066, .479)$ & $.005^{*}$ \\
\cline { 2 - 4 } & Palliative therapy & $.204(.067, .621)$ & $.006^{*}$ \\
\cline { 2 - 4 } & Surgery & $.054(.007, .424)$ & \\
\hline Family attempt suicide previously & No & Reference & $.0001^{*}$ \\
\cline { 2 - 4 } & Yes & $31.466(14.552,68.042)$ & \\
\hline $\begin{array}{l}* \\
\text { indicates variables which show significant factors with suicidal behaviour at multivariate analysis at }\end{array}$ & & \\
\hline
\end{tabular}

\section{Discussion}

Suicide behaviour is by definition, collectively explains words like hopelessness, suicidal thought, intention, organized pan and self-inflicted and/or para-suicide by different things in different settings and conditions.

This study showed that the magnitude of suicide behaviour was $20 \%$.this lower than a study done in Colorado (46.3\%) [12], this discrepancy due to sample size and tool. Whereas it is higher than studies conducted in USA $(0.07 \%)$, Canada $(15.7 \%)$, China $(15.3 \%)$, and Korea $(11.4 \%)[7,8,9,10]$. This might be due to sample size, settings, scale, infrastructure and domestic, and community-based study in the USA.

In the study, cancer like cervical cancer was $3.3 \%$, which is lower than a study done in USA [7]; the magnitude of cervical cancer was $78.1 \%$ and this discrepancy might be due to community-based study and sample size. 
Current treatment regimen (surgery and palliative care) were significantly protective factors for suicidal behaviour and this result is contrasted with a study done in China [9), which were associated factors. It might be due to tool, settings and sample size of the population.

No comorbid physical illness and suicide attempt were significant factors of suicidal behaviour but not in other studies.

\section{Conclusion}

No comorbid physical illness, suicide attempt and current treatment regimen were significant factors of suicidal behaviour.

Recommendation

i. Oncologic professionals should assess patient suicidal risk assessment routinely and should put the diagnosis with suicidal if the client is suicidal so that every professional focuses on management besides the medication.

ii. Oncologic professionals should assess patient whether he/she has a comorbid physical illness or not to prevent the complication of cancer together with suicide which in turn refused to take proper management because of hopelessness.

iii. Educate the family/caregivers of suicidal patients with previous attempts, suicidal thought and intention to have closely followed up.

iv. It is also recommended researchers to conduct further research studies.

\section{Limitation Of The Study}

Inspite of providing valuable baseline data, there are also some limitations encountered:

- Social interest bias as the data was collected by a face to face an interviewer-administered approach. So the respondents might reply in favour of others that are either over-reporting or underreporting because of the illness severity.

- Recall bias; there might be forgetfulness and there was not cross-check about the information they gave us because treatment and/or healthcare service.

- In this study, only adult oncologic patients were included, so it is difficult to generalize all oncologic patients because children and adolescents oncologic patients are not included in the study.

\section{Abbreviations}




\begin{tabular}{ll}
\hline AOR & Adjusted odds ratio \\
\hline CI & Confidence interval \\
\hline HDI & Human Development Index \\
\hline OSSS & Oslo social support scale \\
\hline SBQ-R & Suicidal Behavior Questionnaire-Revised \\
\hline SPSS & Statistical Package for Social Sciences \\
\hline
\end{tabular}

\section{Declarations}

\section{Acknowledgements}

Our sincere thanks go to Mekelle University College of Health Sciences, department of oncology and psychiatry for its provision of the chance to conduct this study. I would like to thank Ayder comprehensive specialized and Quiha General Hospital staffs for the information given on oncologic outpatient units and data used for this research, data collectors, and participants without whom this thesis would not be realized.

\section{Authors' contributions}

The principal investigator was AT. All authors contributed to the study conception and design. Material preparation, data collection and analysis were performed by AT, WM and BG. The first draft of the manuscript was written by Abreha Tsegay and all authors commented on previous versions of the manuscript. All authors read and approved the final manuscript.

\section{Research involving human participants or others}

The study was approved by Mekelle University, Health Science office of Health Research Ethics Review Committee (HRERC) with the reference number of Notification of Expedited Approval ERC 1301/2019 and certifies that the study was performed following the ethical standards.

\section{Informed consent}

All participants have individual rights that are not to be infringed. Individual participants in studies have, for example, the right to decide what happens to the identifiable personal data gathered, to what they have said during a study or an interview, as well as to any photograph that was taken.

\section{Funding}

Not applicable for this section but the assumption source of funding is Mekelle University, College of Health Science. 


\section{Availability of data and materials}

All availability of data and material is attached to the manuscript.

\section{Ethics approval and consent to participate}

This study was carried out after obtaining ethical approval from Mekelle University, College of Health Science office of Health Research Ethics Review Committee (HRERC) with the reference number of Notification of Expedited Approval ERC 1301/2019.

Permission letter was obtained from Mekelle University to oncologic clinics, and finally, the letter was distributed to oncologic professionals, data collectors, who work in the oncologic clinics. Verbal consent was attained from each participant before starting data collection. Study participant had the right to withdraw from the study at any time and information was recorded anonymously.

\section{Consent for publication}

Consent of publication for this research is Mekelle University, College of health science, oncology and psychiatry department and participants.

\section{Competing interests}

We three authors declare that we have no conflict of interest for example on financial support for educational programs, employment or consultation, support from a project sponsor, position and/or rank on advisory board or else type of management relationships and multiple affiliations.

\section{References}

1. Bray F, Ferlay J, Soerjomataram I, Siegel RL, Torre LA, Jemal A. Global cancer statistics 2018 : GLOBOCAN estimates of incidence and mortality worldwide for 36 cancers in 185 countries. CA: a cancer journal for clinicians. 2018 Nov; 68(6):394-424.

2. Global Cancer Facts \& Fig. 4th Edition. Estimated Number of New Cancer Cases by World Area, 2018.American cancer society. P 1-3.

3. Ferlay JGLOBOCAN. 2018. Lyon: World Health Organization International Agency for Research on Cancer, 2018.

4. World Health Organization. Guide to cancer early diagnosis. p 6-9.

5. Resolution WHA67.19. Strengthening of palliative care as a component of comprehensive care throughout the life course. 24. Geneva: In: Sixty-seventh World Health Assembly; May 2014.

6. Poorolajal J, Esmailnasab N, Ahmadzadeh J, Motlagh TA. The Burden of Premature Mortality in Hamadan Province in 2006 and 2010 Using Standard Expected Years of Potential Life Lost: A Population-based Study. Epidemiol Health. 2012;34:1-7.

7. World Health Organization (WHO). 2014. Preventing suicide: A global imperative. 2014. 2-7 p. 
8. Sadock BJ, Sadock VA, Ruiz P. Kaplan \& Sadock's Synopsis of Psychiatry. Behavioral Science/Clinical Psychiatry. eleventh ed. Lippincott Williams \& Wilkins, New York; 2014. 1642-44 p.

9. Gvion Y, Apter A. Suicide and Suicidal Behavior. Public Health Rev. 2012;34(2):1-20.

10. Violette CJ, Mandelbaum RS, Nusbaum DJ, Duval CJ, Matsuzaki S, Machida H, Roman LD, Matsuo $\mathrm{K}$. Temporal trends and characteristics of suicide among women with gynecologic malignancy in the United States. Gynecologic oncology reports. 2019 Nov 1; 30:100510.

11. Henry M, Rosberger Z, Bertrand L, Klassen C, Hier M, Zeitouni A, Kost K, Mlynarek A, Richardson K, Black M, MacDonald C. Prevalence and risk factors of suicidal ideation among patients with head and neck cancer: a longitudinal study. Otolaryngology-Head Neck Surgery. 2018 Nov;159(5):84352.

12. Hong BL, Li SH, Live SY, Tina SL, Liu ZD, Li XB, Zhan HQ, Tao R, Zhang W, Zhou CJ. Suicidal ideation among Chinese cancer inpatients of general hospitals: prevalence and correlates. Oncotarget. 2017 Apr;11(15):25141. 8(.

13. Kim JM, Jang JE, Stewart R, Kim SY, Kim SW, Kang HJ, Shin IS, Park MH, Yoon JH, Yoon JS. Determinants of suicidal ideation in patients with breast cancer. Psycho-Oncology. 2013 Dec;22(12):2848-56.

14. Trevino KM, Balboni M, Zollfrank A, Balboni T, Prigerson HG. Negative religious coping as a correlate of suicidal ideation in patients with advanced cancer. Psycho-Oncology. 2014 Aug;23(8):936-45.

15. Kolva E, Hoffecker L, Cox-Martin E. Suicidal ideation in patients with cancer: A systematic review of prevalence, risk factors, intervention and assessment. Palliative \& supportive care. 2019 Sep 26:1-4.

16. Wang SM, Chang JC, Weng SC, Yeh MK, Lee CS. Risk of suicide within 1 year of a cancer diagnosis. International journal of cancer. 2018 May 15; 142(10):1986-93.

17. Lu D, Fall K, Sparén P, Ye W, Adami HO, Valdimarsdottir U, Fang F. Suicide and suicide attempt after a cancer diagnosis among young individuals. Annals of oncology. 2013 Dec 1; 24(12):3112-7.

18. Akechi T, Okamura H, Kugaya A, Nakano T, Nakanishi T, Akizuki N, Yamawaki S, Uchitomi Y. Suicidal ideation in cancer patients with major depression. Jpn J Clin Oncol. 2000 May;1(5):221-4. 30(.

19. Rueda-jaimes GE, Corzo-casasadiego JD, Moreno-quijano C, Camacho PA. The validity of the Suicide Behaviors Questionnaire-Revised in patients with short-term suicide risk. Eur J Psychiatry. 2017;30(20):30-6.

20. Kocalevent R, Berg L, Beutel ME, Hinz A, Zenger M, Härter M, et al. Social support in the general population: standardization of the Oslo social support scale (OSSS-3). BMC Psychol BMC Psychology. 2018;6:31.

\section{Figures}




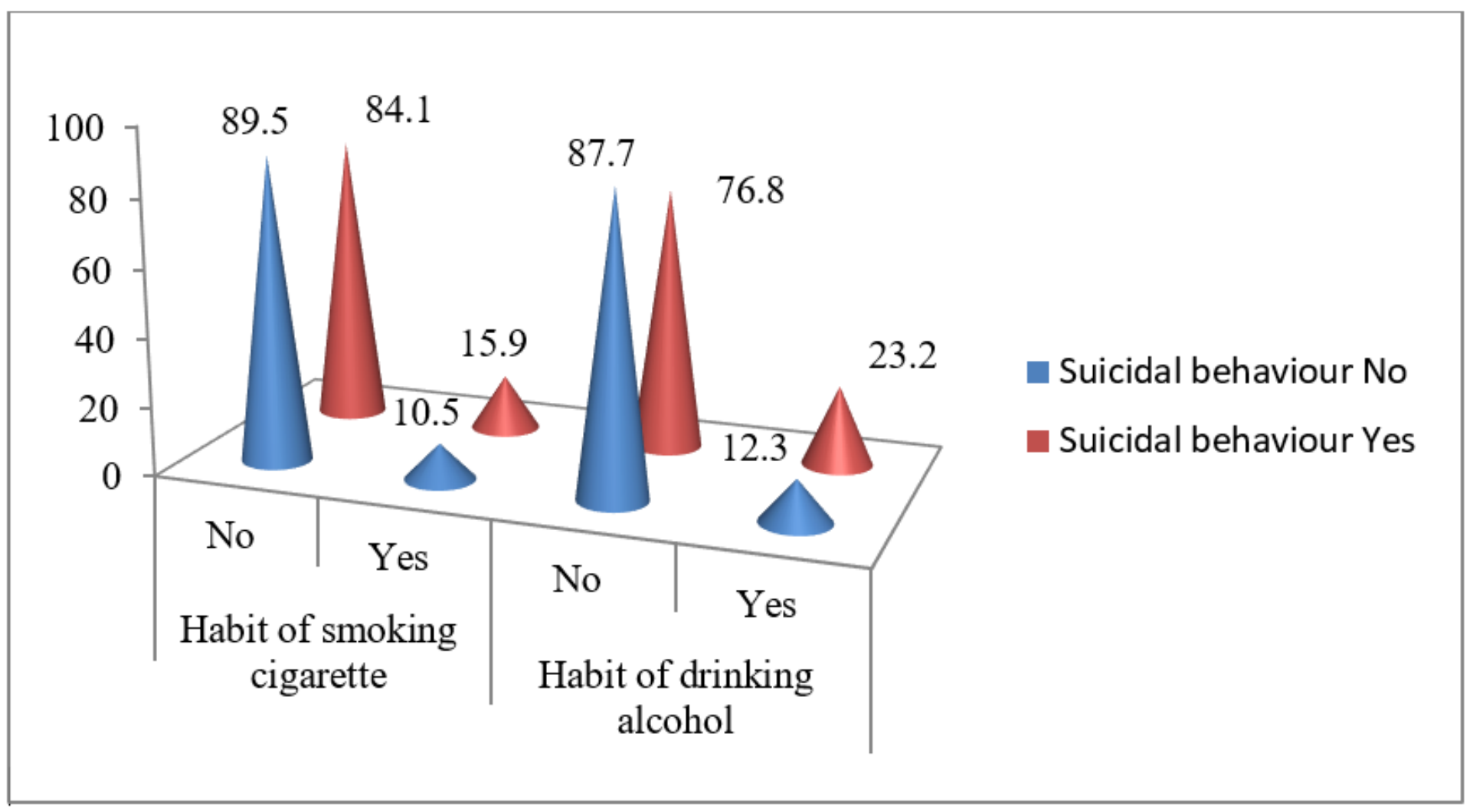

Figure 1

Substance characteristics among cancer patients visiting the oncology outpatient unit in Mekelle oncologic clinics, Tigray, Ethiopia, 2019 ( $N=345)$. 


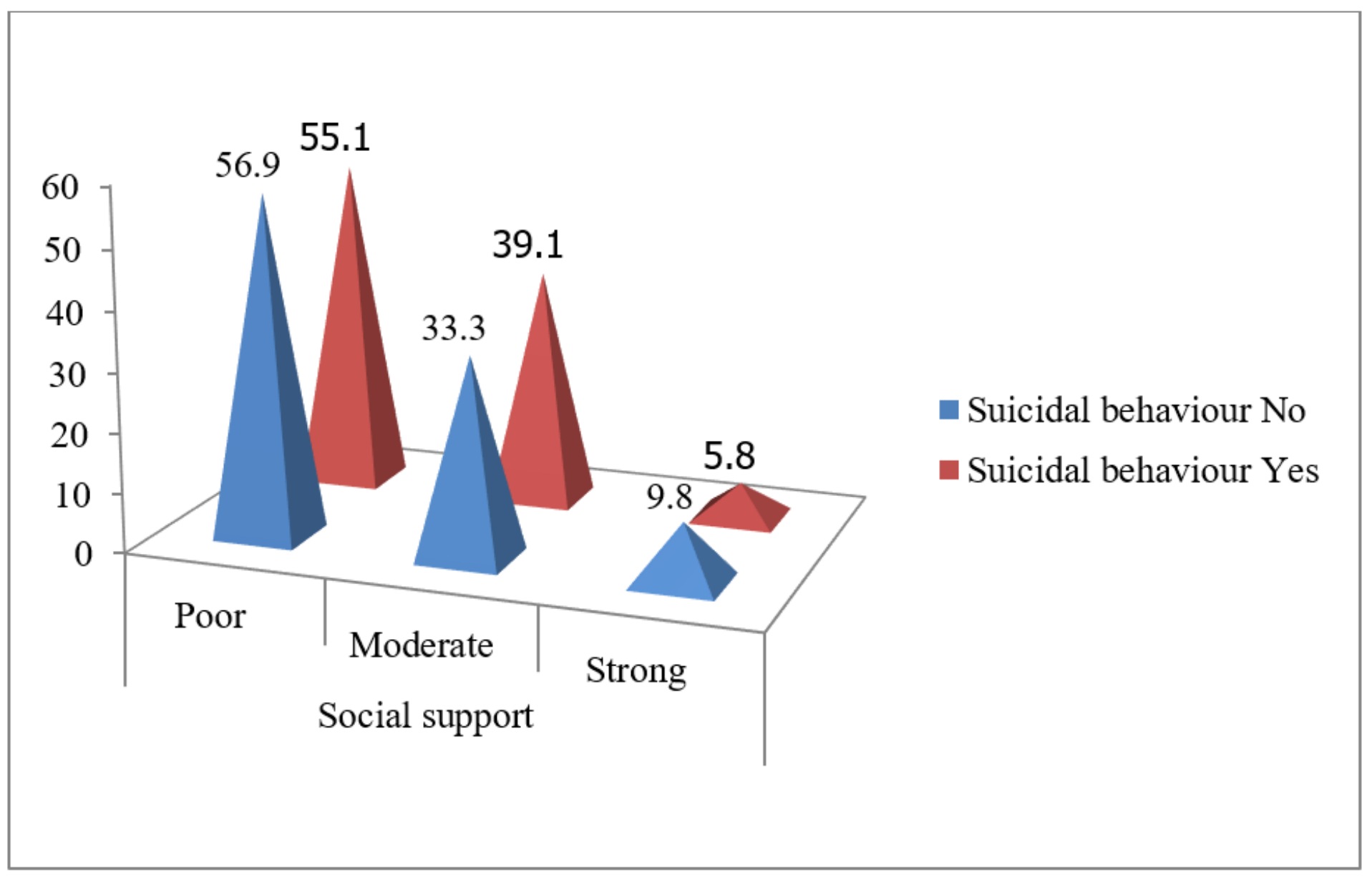

Figure 2

Social support characteristics among cancer patients visiting the oncology outpatient unit in Mekelle oncologic clinics, Tigray, Ethiopia, 2019 ( $\mathrm{N}=345)$. 